\title{
Sex allocation, inbreeding, and mea- sures of population differentiation in hermaphroditic metapopulations
}

\author{
Camille Roux ${ }^{1,2}$, Charles Mullon ${ }^{1}$, Samuel Neuenschwander ${ }^{1,3}$, John R. Pannell ${ }^{1}$ \\ ${ }^{1}$ Department of Ecology and Evolution, Biophore Building, University of Lausanne, 1015 Lausanne, Switzerland \\ ${ }^{2}$ Univ. Lille, CNRS, UMR 8198 - Evo-Eco-Paleo, F-59000 Lille, France \\ ${ }^{3}$ Vital-IT, Swiss Institute of Bioinformatics, 1015 Lausanne, Switzerland
}

ఐ: john.pannell@unil.ch

\section{ABSTRACT}

S election in inbreeding populations is expected to favour female-biased sex ratios in dioecious or gonochoristic species as a result of local mate competition, a prediction that finds strong support in populations in which females have control of the proportion of their sons versus daughters. Local mate competition due to inbreeding should also promote female-biased sex allocation in hermaphrodites, with reduced emphasis on the production of sperm or pollen relative to eggs, ovules or seeds. While inbreeding can be the direct result of the mating system in local populations, it can also result from demographic causes such as population turnover in metapopulations with frequent local extinction and recolonization. This effect of the turnover of demes has previously been analysed under the 'haystack model' for species with separate sexes. Here, we use quantitative genetic simulations to ask how population turnover affects the evolution of sex allocation in hermaphroditic metapopulations, and we assess the extent to which different genetic measures of inbreeding and population differentiation, especially FST and Jost's D, predict the equilibrium sex allocation. We find that population turnover may dramatically enhance the female bias of hermaphroditic metapopulations, particularly where the inter-deme migration rate is low, even where local inbreeding, measured by FIS, is low or absent. In such situations, FST is a good predictor of the equilibrium sex allocation, and much better than Jost's D. Our study extends predictions for sex allocation in subdivided populations that might experience population turnover to hermaphroditic species, and draws attention in general to the power of Wright's hierarchical inbreeding statistics to predict the sex allocation in metapopulations at equilibrium.

\section{Contents}

1 Introduction

2 Model 3

2.1 Overview ............ . 3

2.2 Architecture of sex allocation . . . . 3

2.3 Architecture of neutral loci . . . . . . 3

2.4 Mating and seed production ..... . 3

2.5 Population growth of local demes ... 4

2.6 Metapopulation dynamics: migration, extinction and colonisation . . . . . 4 4

2.7 Implementation, simulation runs, and variables measured . . . . . . . . 4

3 Results 4

3.1 Accuracy of our simulations . . . . . 4

3.2 Effects on sex allocation of inbreeding and metapopulation dynamics . . . . 4

3.3 Relationship between sex allocation and statistics for population differentiation

4 Discussion 
bioRxiv preprint doi: https://doi.org/10.1101/2020.05.08.080929; this version posted May $9,2020$. The copyright holder for this preprint (which was not certified by peer review) is the author/funder, who has granted bioRxiv a license to display the preprint in perpetuity. It is made available under aCC-BY-NC-ND 4.0 International license.

Sex allocation, inbreeding, and measures of population differentiation in hermaphroditic metapopulations

4.1 Effects of population turnover on sex allocation in hermaphroditic metapopulations . . . . . . . . . . .

4.2 Evaluation of statistics for inbreeding and population differentiation in the context of sex-allocation evolution . . .

\section{Introduction}

'Sex allocation' refers to the proportion of reproductive resources an individual invests in its male versus female sexual functions. In dioecious or gonochoristic species, it is synonymous with the sex ratio of sons and daughters produced by mothers, weighted by the relative cost of raising an offspring of each sex to independence. The fact that many species produce equal sex ratios once seemed puzzling, as males represent a wasted resource from the perspective of the potential intrinsic growth of a population. Düsing [1] first provided an evolutionary explanation for equal sex ratios, although the idea is often credited to Fisher [2]. Simply put, because autosomal genes have an equal chance of passing to the next generation through male and female gametes, selection should favour investment in the success of each of these two paths. The corollary is that, in populations with an unequal sex ratio, selection will favour alleles in the minority sex, because they must, on average, leave more progeny than those of the majority sex. In such populations, natural selection should thus rapidly bring about equilibration of the sex ratio.

Although equal sex ratios are common, many species produce female-biased sex ratios, with more daughters than sons. Hamilton [3] explained these 'extraordinary sex ratios' largely in terms of the effects of 'local mate competition'. If mating is not random, and, in particular, if sons must compete among themselves for mating with a restricted number of females, selection should favour a strategy that biases the sex ratio towards the production of fewer sons and more daughters [4]. Hamilton's [3] explanation is supported by a wide range of empirical observations, and indeed stands as perhaps the most successful cornerstone of life-history theory [reviewed on page 84 in [5]]. It is particularly well illustrated by examples where the sons and daughters of a small number of fertilized females hatch together and mate before dispersing [6]; when the number of mothers is small, the chance of mating between full or half siblings (inbreeding) is high. Indeed, the inbreeding coefficient, which measures the degree to which related individuals mate with one another relative to the case of random mating across the population, is a reliable predictor of sex ratio chosen by mothers for their progeny [7-14]. The rate of dispersion can similarly vary between sexes in a gonochoristic metapopulation. Thus, the evolutionarily stable sex-specific dispersion rates depend in part on the relatedness coefficient $R$, defined as $\frac{2 . F_{S T}}{1+F_{I T}}$ in an inclusive fitness model, meaning that a costly dispersion will be more likely to evolve if the population is genetically structured [15].

While the above ideas were developed principally with gonochoristic species in mind and have found substantial support from studies of species with separate sexes (though see [16]), they also apply to hermaphrodites [5, 17-20]. Hermaphrodites do not generally produce sons or daughters, but their sex allocation can be viewed in terms of the relative investment they make to their male versus female functions, e.g., to sperms versus eggs or, for seed plants, to pollen versus seeds - even though these relative investments may be difficult to compare directly (see Discussion). Just as for the sex ratios in species with separate sexes, selection on the sex allocation of hermaphrodites should favour equal investment in both sexual functions if mating is random and both pollen and seeds are widely dispersed [21]. Indeed, limited dispersal can cause sib competition, and theory predicts that the sex ratio should be biased in favour of the sex that shows the smaller degree of competition between siblings [2124] (although it is often supposed that hermaphroditic plants invest more heavily in their female function, which involves the production of flowers, seeds and fruit, measures of the cost of male investment in terms of trade-offs with growth show that it, too, can be high and can equal or even surpass the costs of female function; [25]).

Just as for dioecious species or gonochorists, hermaphrodites in populations subject to local mate competition are expected to bias their sex allocation to their female function. Thus, female-biased allocation is predicted for plants where pollen is dispersed to a limited number of receptive flowers [21]. Similarly, female-biased allocation is predicted for partially inbreeding hermaphroditic populations $[17,19,26$, 27]. The expected female-biased sex allocation of inbreeding hermaphrodites is well supported by empirical data, particularly comparisons between populations or species that have different rates of self-fertilization $[5,18,20]$. For instance, plant populations that have undergone a transition from outcrossing to selfing often quickly evolve a 'selfing syndrome', which includes reduced allocation to pollen and traits that play a role in pollen dispersal [26-28]. Although this has been attributed to the 'greater efficiency' of self-fertilizing plants [28], their reduced allocation to male function is better seen as an illuminating example of selection under local mate competition (or 'local sperm competition; [20, 29], where pollen grains (or sperm) from the same individual compete to fertilize its own restricted pool of ovules (or eggs).

Self-fertilization represents the most extreme form of inbreeding, but strong population structure can also bring about inbreeding. In demographically stable plant populations in which seeds and pollen are dispersed over short distances, mating partners will often be more closely related than individuals drawn ran- 
bioRxiv preprint doi: https://doi.org/10.1101/2020.05.08.080929; this version posted May $9,2020$. The copyright holder for this preprint (which was not certified by peer review) is the author/funder, who has granted bioRxiv a license to display the preprint in perpetuity. It is made available under aCC-BY-NC-ND 4.0 International license.

Sex allocation, inbreeding, and measures of population differentiation in hermaphroditic metapopulations

domly from the population [30], although the levels of inbreeding brought about by such population viscosity are relatively mild compared with self-fertilization. By contrast, we might expect species subject to metapopulation dynamics, i.e., frequent local extinctions and recolonizations, to show high levels of inbreeding, too [31]. For instance, populations founded by one or a few individuals may grow to large local sizes over the course of a few generations [32]. Because all individuals will be closely related through their descent from recent colonisers [32-35], we should still expect metapopulation dynamics to bring about selection for female-biased sex allocation due to inbreeding, even if mating is random when populations become large. To our knowledge, this prediction has not yet been examined in any detail for hermaphrodites, though Aviles [36] used simulations to show that metapopulation dynamics favoured a bias in the sex ratio of gonochorists. How rapid must population turnover be for selection to favour an appreciable shift in the sex allocation of a hermaphroditic metapopulation? And what index of inbreeding would be the best predictor of the sex allocation selected?

Here, we use quantitative genetic simulations of hermaphroditic metapopulations to demonstrate that population turnover should select for female-biased sex allocation as long as migration among demes is insufficiently strong to erase the genetic signatures of inbreeding brought about by colonisation. Moreover, we find that the inbreeding coefficient $F_{S T}$ is a much better predictor of the sex allocation selected in such a situation than $F_{I S}$, which has proven adequate to predict the sex allocation within single viscous populations, as noted above. Although the importance of $F_{S T}$ as a predictor of sex allocation in metapopulation has hitherto not been emphasised, our result should be intuitive: what brings about local mate competition in a metapopulation is the effect of extinctions and colonisations on population differentiation, which is well described by $F_{S T}$. Interestingly, our simulations also indicate that Jost's $D$ [37] is a poorer indicator than $F_{S T}$ of when to expect selection to shift the sex allocation of a metapopulation. There has been substantial discussion about the relative merits of Jost's $D$ versus $F_{S T}$ (and its multiallelic equivalent, $G_{S T}$ ) as measures of genetic differentiation [38-44]. While the results of our study do not address this issue directly, they do resonate with the view [e.g., [38] ] that $F_{S T}$ should be a preferred measure of genetic differentiation when we wish to draw from it inferences relevant to evolutionary process.

\section{Model}

\subsection{Overview}

We assumed a multi-deme metapopulation made up of hermaphrodites that varied in their sex allocation as a function of the additive effects of alleles at a single sex-allocation locus subject to recurrent mutations that alter the allelic effects. Mating within demes and seed production depended on the sex allocations of individuals within the deme. Seed production influenced both local population growth and the dispersal of individuals (and genes) among demes; we assumed no gene flow through pollen. Demes were subject to recurrent stochastic extinction. After extinction of a deme, its site was assumed to be immediately recolonized through seed dispersal from the rest of the metapopulation. Recurrent mutations altered both the allelic effects at the sex-allocation locus as well as allelic states at several neutral loci.

\subsection{Architecture of sex allocation}

Each individual allocated a proportion $\alpha$ and $\beta$ of its resources toward male and female functions respectively, with $\alpha+\beta=1$. The value of $\alpha$ and $\beta$ for a given individual was determined by the additive allelic effects at a single multi-allelic locus, with each allele, $i$, taking a value $0 \leq q_{i} \leq 0.5$, and determined by the sum of the effects of both alleles, $\alpha=q_{1}+q_{2}$. Prior to mating, at the time of gamete production, each sex-allocation allele in a given individual mutated to a new value with probability $\mu . q$, in which case the new allelic effect $q_{i}$ was determined by multiplying the old value by a random variable drawn from a Uniform distribution on $[0.9-1.1]$. If the new value of $q>0.5$, it was truncated to 0.5 . Although this is a somewhat unrealistic architecture for a quantitative locus, it served the purpose of allowing sex-allocation parameter space to be fully explored for $0 \leq \alpha \leq 1$. Simulations of an alternative multi-locus model were substantially slower to run but yielded quantitatively similar results.

\subsection{Architecture of neutral loci}

In addition to the sex-allocation locus, individuals also carried 20 neutral loci, each occupied by two alleles labelled from the set of integers between 1 and 1000. We assumed that all simulated loci were located on different chromosomes and were independently transmitted to offspring, with no linkage to the sex-allocation locus. Prior to mating, each neutral allele has a probability $\mu$ n of mutating to a new allele, which involves randomly drawing a new integer label from the set. As indicated in the Results, estimation of diversity and inbreeding statistics based on our simulations of this finite alleles model conformed accurately to predictions from population genetic models for subdivided populations.

\subsection{Mating and seed production}

Individuals contributed to the next generation as mothers and fathers as a function of their sex allocation, i.e., mating assumed a mass-action model. An individual's 
bioRxiv preprint doi: https://doi.org/10.1101/2020.05.08.080929; this version posted May $9,2020$. The copyright holder for this preprint (which was not certified by peer review) is the author/funder, who has granted bioRxiv a license to display the preprint in perpetuity. It is made available under aCC-BY-NC-ND 4.0 International license.

Sex allocation, inbreeding, and measures of population differentiation in hermaphroditic metapopulations

seed production was determined by the product of its female allocation, $\beta$, and a fertility parameter $F$, which was fixed for each simulation run; $F$ regulated the local population growth rate (see below). Because the product $\beta . F$ is generally a real number rather an integer, the number of seeds produced by an individual was in practise calculated as the value of its truncation to an integer incremented by one with a probability given by the fractional remainder (for example, if $\beta . F=3.7$, the individual was assigned a production of 3 seeds with probability 0.3 and 4 seeds with probability 0.7.) The mother of each new seed was determined by random sampling among individuals in the deme, with the probability of being chosen each time weighted by the individual's value of $\beta$. Each new seed's father was determined similarly by a random sampling across the deme, weighted by its $\alpha$. The pollen and ovule alleles for each new seed progeny were sampled randomly from the chosen parent (with a 0.5 probability of choosing each allele for each locus).

\subsection{Population growth of local demes}

We simulated a finite-island metapopulation of $D$ demes with discrete, non-overlapping generations. All of the $D$ demes were occupied by $N$ individuals, where $0 \leq N \leq K$, and $K$ is the carrying capacity. Population growth of a particular deme was determined by its current $N$, the parameter $F$, and the values of female allocation, $\beta$, of its constituent individuals (prior to mutation). Specifically, if $N_{t=0}$ was a deme's size prior to reproduction, its new size after reproduction $N_{t=1}$ was given by the sum of $\beta$.F over the $N_{t=0}$ individuals. $N_{t=1}$ was truncated at the population carrying capacity $K$, if exceeded.

\subsection{Metapopulation dynamics: migra- tion, extinction and colonisation}

After mating and reproduction, each deme received migrants from the rest of the metapopulation, with their number sampled from a Poisson distribution with mean $I$. For a given deme, immigrants were drawn from a random sample of the whole metapopulation, i.e., we effectively assumed that migrants came from a global migrant-pool. Migrants added to the number of individuals in a deme, and if their carrying capacity was reached, immigrants replaced local individuals chosen at random.

Following migration, each deme became extinct with probability $E$; individuals in such demes were immediately replaced by $k$ colonist individuals sampled according to 'propagule-pool' colonisation [45, 46]. Specifically, a source deme was chosen at random from the metapopulation, weighted by its seed production (see below), and all $k$ individuals were then drawn from that deme to repopulate the extinct deme. We assumed that demes that became extinct did not contribute to the migrant or propagule pool themselves.

\subsection{Implementation, simulation runs, and variables measured}

The model was implemented in $\mathrm{C}$, with the code freely available (https://github.com/popgenomics/ quantiSex). We initially tested our simulations by comparing the results for neutral variation with predictions of population genetic models [31, 45-47]. We also established run times necessary for equilibration of the metapopulation sex allocation. We explored parameter space by choosing domains that seemed most interesting and revealing, with all runs replicated multiple times (see Results). We computed statistics for neutral population diversity and differentiation, and for sex allocation, after reproduction. Population genetics statistics $F_{S T}, F_{I S}, F_{I T}, G_{S T}, G_{S T}^{\prime}, G_{S T}^{\prime \prime}$ and $D_{\text {jost }}$ were computed internally and by calling the R library 'diveRsity' [48].

\section{Results}

\subsection{Accuracy of our simulations}

We first tested the implementation of our model by comparing its output for differentiation statistics with those predicted by theory $[47,49]$, by measuring the residuals $R=F_{S T-E x p e c t e d}-F_{S T-\text { Simulated. }}$. Our simulation results were very close to those predicted by theory, with the absolute median difference in $F_{S T}$ between predicted and simulated values being 0.014 ( \pm 0.026 ; Fig. S1). The distribution of $R$ values from -0.011 to 0.05 (Fig. S1) indicates a slight tendency to underestimate genetic differentiation. This bias is likely attributable to the fact that the analytical predictions are based on a model that assumes an infinite number of demes: when we simulated metapopulations with an increased number of demes, the bias was reduced. Overall, we are satisfied that our implementation produces the same effects of metapopulation dynamics on genetic differentiation as predicted by an analytical model [49].

\subsection{Effects on sex allocation of inbreed- ing and metapopulation dynamics}

In metapopulations with no population turnover (extinction $=0$ ), our simulation retrieved the expected dependence of sex allocation on local inbreeding (caused by self-fertilization and measured at $\left.F_{I S}\right)$. Thus, in the absence of inbreeding $\left(F_{I S}=0\right)$, hermaphrodites evolved a sex allocation of 0.5 , a value that increased with greater inbreeding and reached 1.0 when individuals were completely self-fertilizing $\left(F_{I S}=1.0\right)$ (Fig. 1, lower curve; and Fig. S2). Population turnover (extinction $>0$ ) caused selection to favour hermaphrodites with female-biased sex allocation for 
bioRxiv preprint doi: https://doi.org/10.1101/2020.05.08.080929; this version posted May $9,2020$. The copyright holder for this preprint (which was not certified by peer review) is the author/funder, who has granted bioRxiv a license to display the preprint in perpetuity. It is made available under aCC-BY-NC-ND 4.0 International license.

Sex allocation, inbreeding, and measures of population differentiation in hermaphroditic metapopulations

a given local selfing rate, especially when populations were recolonized by a small number of individuals, $k$ (Fig. 1). Hermaphrodites were particularly femalebiased when the effects of self-fertilization were coupled to the effects of population turnover, especially when migration between demes was low or absent (Fig. S2).

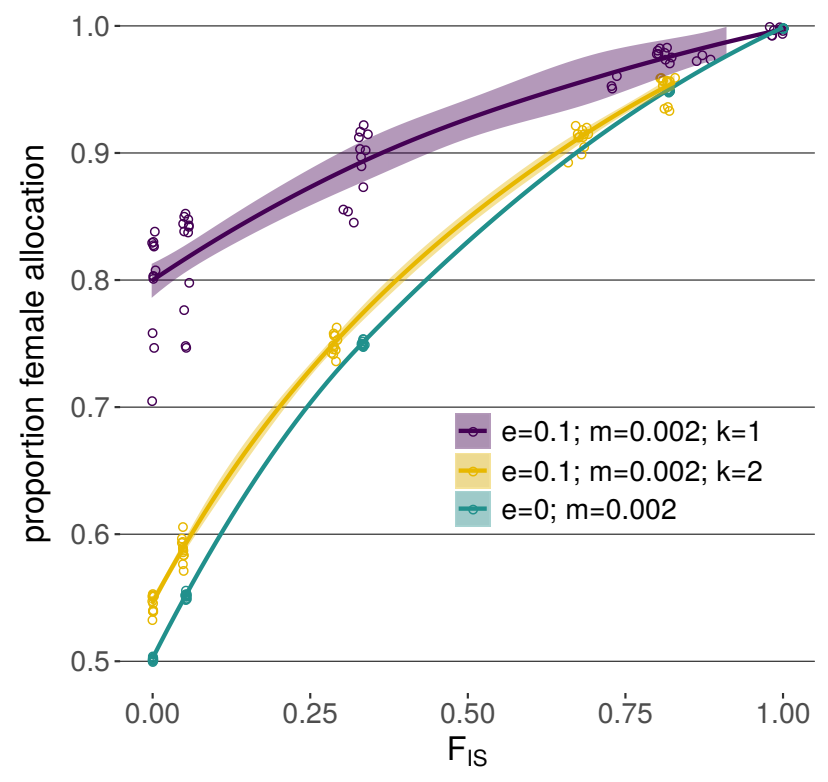

Figure 1. Female allocation at equilibrium as a function of $F_{I S}$ and in response to population turnover through extinction-recolonization dynamics and for different rates of local inbreeding. $e, m$ and $k$ designate the extinction rate, migration rate and number of recolonizing individuals, respectively. Under each different combination for these three parameters, we explored five selfing rate values, with $s$ in $[0,0.1,0.5$, $0.9,1]$.

The relative effects of migration and extinction on equilibrium female allocations are illustrated in Fig. 2 for $k=1$ and $k=2$. Overall, our results indicate that population turnover selects for a female-biased sex allocation, an effect that is ameliorated by inter-deme migration, which effectively erases the effects of extinction, $E$. Thus, in the complete absence of migration $(m=0)$, even small values of $E$ led to strongly femalebiased hermaphrodites, with female allocation showing a median of 0.99 for our runs for $k=1$, and a median of 0.79 for $k=2$. In contrast, higher extinction rates were required to maintain female-biased allocation in the face of increased gene flow (Fig. 2A), or when the bottlenecks of colonization were reduced because demes were founded by larger numbers of colonists (Fig. 2B).
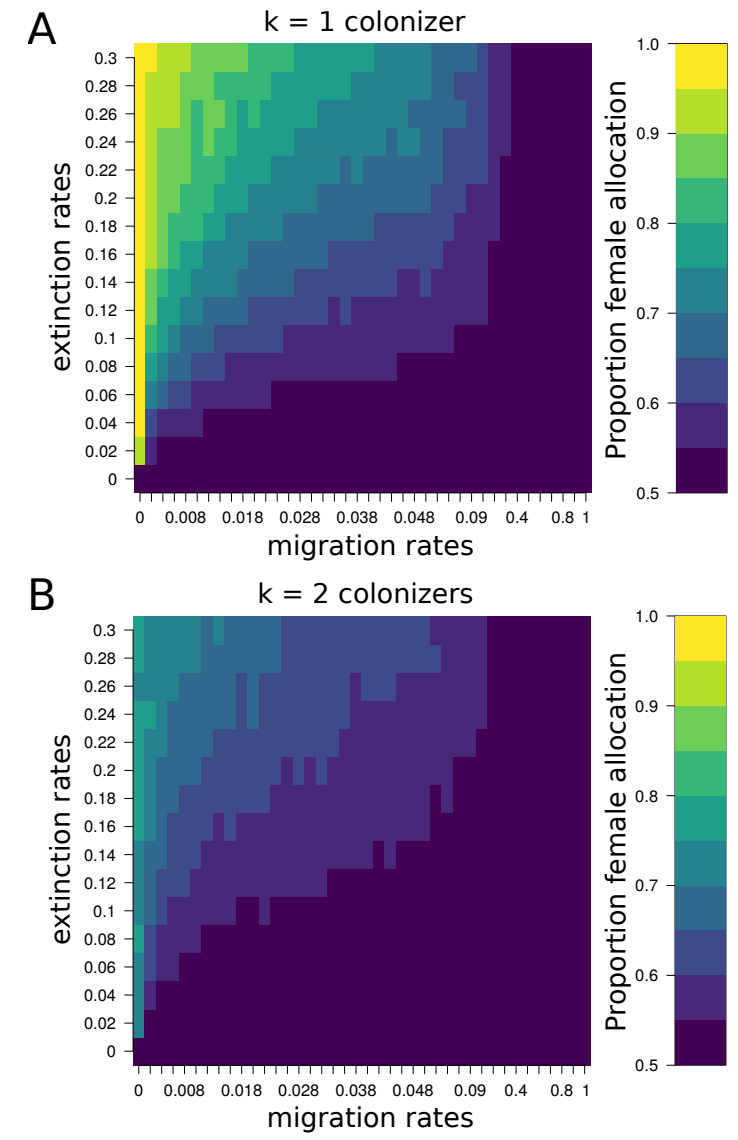

Figure 2. Effect of migration and extinction rates on the female allocation in a hermaphroditic metapopulation. Colours show the average female allocation measured over the metapopulation at equilibrium, on a scale from 0.5 (blue: $50 \%$ of female allocation) to 1 (yellow: $100 \%$ of female allocation). Extinction represents the probability per generation that a deme has its individuals removed from the metapopulation and replaced by $k$ colonists. Migration is the proportion of individuals per generation and for a given deme that immigrate from other demes. The results are shown for the case where recolonization is the result of by (A) $k=1$ and (B) $k=2$ individuals. For each parameter combination, results are given in terms of the median female allocation over the whole metapopulation and over ten independent iterations.

\subsection{Relationship between sex alloca- tion and statistics for population dif- ferentiation}

As expected, both $F_{S T}$ and $G_{S T}$ were monotonically decreasing functions of the migration rate for a given extinction rate (Fig. 3A and 3B). Whereas Jost's $D$ and $G_{S T}^{\prime}$ decreased monotonically with migration in the absence of extinction, this relationship became reversed with population turnover, an effect particularly pronounced for Jost's $D$ (Fig. 3C and 3D). For example, although $F_{S T}=1.0$ at equilibrium (in the complete absence of migration) and for any extinction value, 
bioRxiv preprint doi: https://doi.org/10.1101/2020.05.08.080929; this version posted May $9,2020$. The copyright holder for this preprint (which was not certified by peer review) is the author/funder, who has granted bioRxiv a license to display the preprint in perpetuity. It is made available under aCC-BY-NC-ND 4.0 International license.

Sex allocation, inbreeding, and measures of population differentiation in hermaphroditic metapopulations

the equilibrium value Jost's $D$ could approach zero in metapopulations with increased population turnover, even in the absence of any migration among demes.
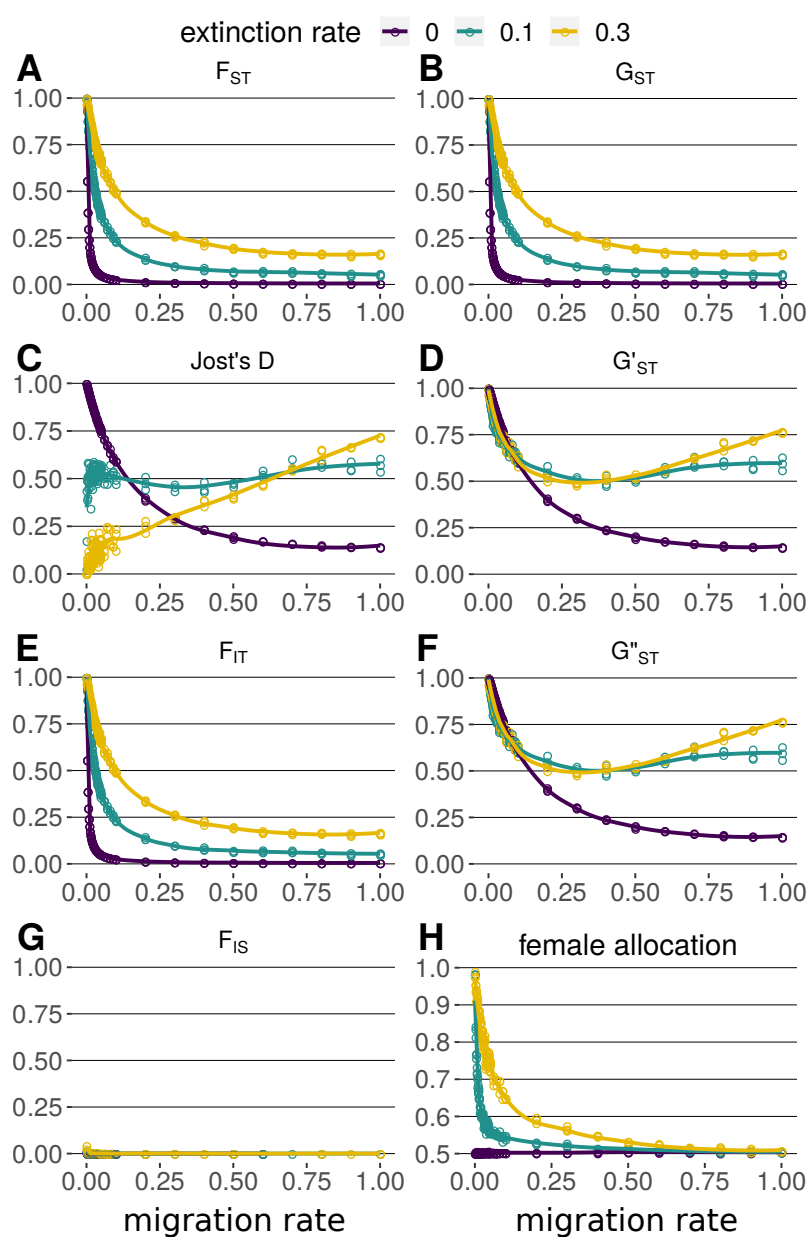

Figure 3. Effects of migration and extinction rates on various genetic and phenotypic variables for $k=1$ colonists. The lines indicate different extinction rates explored: 0 (violet), 0.1 (blue) and 0.3 (yellow).

Consistent with these complexities, the relationships between female allocation and the different indices of genetic differentiation varied considerably (Fig. 4). Indeed, whereas sex allocation was positively correlated with both $F_{S T}$ (Fig. 4A; Pearson's $R^{2}=0.84$ ) and $G_{S T}^{\prime}$ (Fig. 4B; Pearson's $R^{2}=0.38$ ), the association between female allocation and $D_{\text {Jost }}$ was weaker and negative (Figs. 2-4; Pearson's $R^{2}=0.58$ ).

This difference is probably best explained by differences between the ways $F_{S T}$ and $D_{J o s t}$ are affected by population turnover. In the absence of migration, when female bias is at its maximum, Jost's $D$ tends towards zero with increasing extinction. Note that in simulations that assumed random mating within demes, the selfing rate was effectively $1 / K$ (the inverse of the carrying capacity for full demes). $F_{I S}$ was thus always close to zero (Fig. 3G), and unrelated to the local sex allocation (Figs. 3H and 4D). But increased selffertilization leads to highly biased female allocation

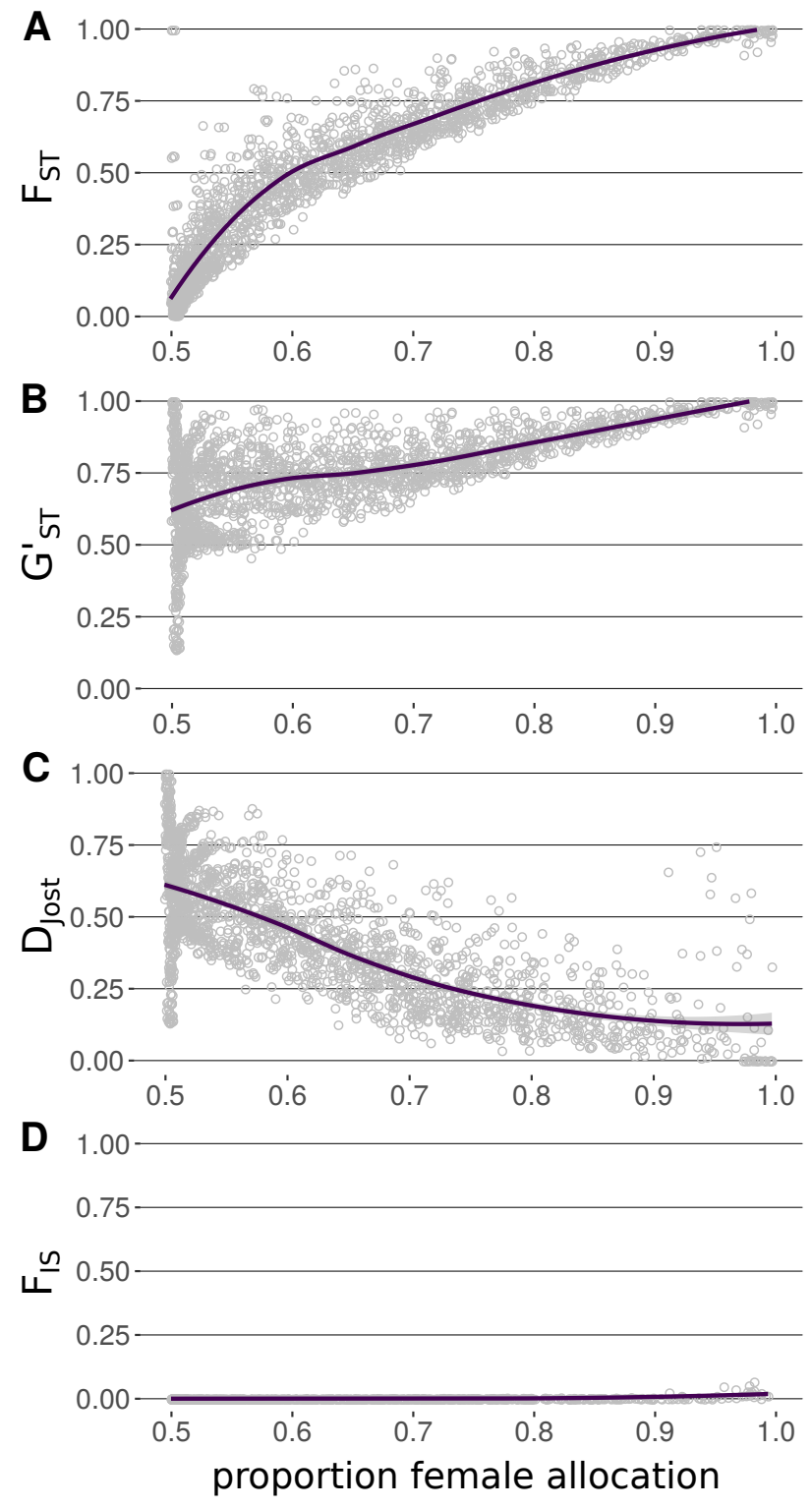

Figure 4. Relation between female allocation and genetic measures of population differentiation or inbreeding. Each points represent an independent simulation. The blue purple represents the loess regression between female allocation and descriptive statistics.

in absence of population turnover (Fig. S2). Thus, when $E=0$, female allocation measured at equilibrium are close to $0.50,0.55,0.75,0.95$ and 0.99 for inbreeding set to $0,0.1,0.5,0.9$ and 1 respectively, with no effect of gene flow between demes. Finally, our simulations captured the expected sensitivity of $F_{S T}$ to the mode of recolonization, i.e., whether it followed a propagule-pool or a migrant-pool model (with colonists drawn from a single or more than one deme, respectively). For example, whereas $F_{S T}$ approached unity under a propagule pool model of colonization, even for $k=10$ (Fig. S4), it remained $<0.5$ under migrant-pool colonisation for $k=2$. Again, this difference was reflected in a corresponding association 
bioRxiv preprint doi: https://doi.org/10.1101/2020.05.08.080929; this version posted May $9,2020$. The copyright holder for this preprint (which was not certified by peer review) is the author/funder, who has granted bioRxiv a license to display the preprint in perpetuity. It is made available under aCC-BY-NC-ND 4.0 International license.

Sex allocation, inbreeding, and measures of population differentiation in hermaphroditic metapopulations

with the equilibrium sex allocation, with greater female bias under the propagule-pool than the migrant-pool model.

\section{Discussion}

\subsection{Effects of population turnover on sex allocation in hermaphroditic metapopulations}

Our study has demonstrated that population turnover in a metapopulation, brought about through local extinctions and recolonizations, selects for female-biased sex allocation in hermaphrodites under a wide range of conditions that can be related to previous theory. The bias in allocation is strongest when the rate of turnover is high, new demes are colonised by small numbers of individuals, and when dispersal among extant demes is low. In contrast, the potential effects of population turnover on biased sex allocation are erased by migration, and when extinct demes are recolonized by individuals drawn from demes across the metapopulation. In general, these results are consistent with population genetic models pointing to the importance of the relative rates of extinction and gene flow by migration for patterns of within-population diversity and among-population differentiation [reviewed in [50]]. Our simulations indicate that this relativity extends to the evolution of sex allocation.

Our finding that metapopulation processes can cause selection to favour hermaphrodites that bias their reproductive resources towards female and away from male function aligns with well-established sex-allocation theory on the effects of inbreeding in general, and inbreeding due to population structure in particular [3]. The classic example that illustrates this effect are the biased sex ratios predicted for and observed in gonochoristic parasitoids or fig wasps, in which a single or few females lay their eggs in hosts of figs, respectively, and the hatching male progeny must compete among themselves to mate with their sisters [51-54]. As noted in the Introduction, under such 'local mate competition', overinvestment in the production of males diminishes the inclusive fitness of an egg-laying mother, who would do better to use her limited eggs to produce more females. The idea that inbreeding should favour a female-biased sex allocation not only in gonochoristic species but also in hermaphrodites is by no means novel. Local mate competition caused by self-fertilizing hermaphroditic plants has long been interpreted as underlying their low pollen-ovule ratios $[18,19,28,55$, $56]$, or their low allocation to pollinator attraction [26], which may be viewed as benefitting male more than female function [57-60]. Similarly, low inferred allocation to male function in hermaphroditic snails and worms has been attributed to local mate competition due to self-fertilization or biparental reproduction in genetically viscous populations [reviewed in [20]].
The importance of our results is thus not so much in demonstrating the effects of local mate competition on sex allocation in a hermaphroditic context, but in drawing attention to the capacity of metapopulation dynamics to bring about sufficiently strong inbreeding to bias a population's sex allocation even in outcrossing hermaphrodite species.

It is revealing to compare our expectations for the sex allocation in hermaphroditic versus gonochoristic or dioecious metapopulations. The very strong female biases in hermaphroditic sex allocation we observed are qualitatively similar to those that have been predicted and reported for the sex ratios of several gonochoristic invertebrates subject to strong population subdivision, strong local inbreeding, and colony turnover $[5,61]$. Importantly, in such species the egg-laying mother is able to control the sex ratio of her progeny. In contrast, gonochoristic species with genetic determination of sex (i.e., in which sex is largely beyond maternal control) tend not to show the substantial biases in sex allocation observed in, e.g., fig wasps, even though they may also be subject to demographic processes involving colonisation and subsequent local inbreeding. An example would be a species with a lifestyle characterised by the 'Haystack model' first introduced by Maynard Smith's [62].

In important respects, the Haystack model is similar to the model we have simulated here. It considers a population of mice that becomes periodically subdivided into small haystack habitat patches for several generations of mating among closely related cohabitants of the patch before haystacks are destroyed and the mice disperse to seek new patches. Bulmer and Taylor [23, 63] and Taylor and Bulmer [4] considered the evolution of the sex ratio under this model and showed that female-biased sex ratios should evolve as a result of local mate competition. But mice, even if they were to live in a metapopulation of haystacks, seem less likely to realise the evolutionary stable sex ratios that theory would predict, because the sex ratio may be constrained by the genetic sex determination, and female mice have less control over it than their fig-wasp counterparts - though see Aviles et al. [16] for an example of realised female-bias in spiders with genetic sex determination. Constraints associated with genetic sex determination likely apply to many species with separate sexes in which strong inbreeding due to metapopulation dynamics does not result in strong female-biased sex ratios. For instance, although the ecology of the dioecious plants Silene latifolia [e.g., [64]] or S. dioica [e.g., [65]] involves population turnover and local inbreeding, sex ratios are typically $1: 1$. Significantly, the sex-determination constraint does not apply to hermaphroditic metapopulations, because selection adjusts the proportion of resources allocated to male versus female function by each individual, and a single monomorphic evolutionary stable sex allocation can be achieved, as illustrated by our simulations. We conjecture, therefore, that the 
bioRxiv preprint doi: https://doi.org/10.1101/2020.05.08.080929; this version posted May $9,2020$. The copyright holder for this preprint (which was not certified by peer review) is the author/funder, who has granted bioRxiv a license to display the preprint in perpetuity. It is made available under aCC-BY-NC-ND 4.0 International license.

Sex allocation, inbreeding, and measures of population differentiation in hermaphroditic metapopulations

processes we have modelled are more likely to give rise to biased sex allocation in hermaphroditic species than in gonochoristic or dioecious species in which sex is determined genetically, even if it will tend to be difficult to calibrate the sex allocation empirically (as noted above).

Despite the difficulties for calibrating the sex allocation of hermaphrodites, is there any empirical evidence for the female-biased sex allocation revealed our simulations from a wild hermaphroditic species? We believe that patterns of sex allocation displayed by monoecious and androdioecious populations of the annual colonising plant Mercurialis annua are consistent with expectations for such female bias. A number of studies indicate that $M$. annua is subject to population turnover $[66,67]$, sufficient to generate the strong population subdivision and inbreeding of the sort that should select for female-biased allocation $[68,69]$. Exceptionally, the $M$. annua species complex presents variation in its sexual systems that allows this conjecture to be tested. In the Iberian Peninsula, the species is a metapopulation comprising monoecious individuals that, in many populations, co-occur with males [70, 71]. This androdioecious dimorphism allows the sex allocation of monoecious individuals to be calibrated against the male allocation of males. Such comparisons indicate that monoecious plants are indeed strongly female-biased in their sex allocation, with the proportion of resources allocated to male function ranging roughly between 0.1 and $0.3[69,71]$. This female bias has been tested though the experimental introduction of males into populations comprising only monoecious individuals; such introductions lead to the rapid increase of the male frequency, consistent with an initial deficit of male allocation at the population level [72]. Importantly, although self-compatible and fully capable of autonomous seed set in the absence of mates, monoecious individuals in established populations are largely outcrossing [73], suggesting that the inferred female-biased sex allocation is not an outcome of selection under habitual selfing and is more likely the effect of the metapopulation processes typifying this ruderal colonising weed. In the light of comments made above about constraints imposed by genetic sex determination, is also noteworthy that sex-ratio bias is never found in dioecious metapopulations of $M$. annua (in which sex determination is chromosomal), even though they occupy similar habitats and have the same colonising ecology [74].

The case of $M$. annua is unusual in being a system that allows sex-allocation calibration and straightforward tests of theoretical expectations, but of course many hermaphroditic plants and animals have colonising histories. While it might be difficult to estimate the absolute investment towards male versus female function in these species, the ideas explored in the current paper might nevertheless be tested in comparisons of allocation to male versus female functions between geographical regions with different histories of coloni- sation. The most promising studies might be those, for example, that compare the reproductive allocations of hermaphrodites at the extreme edge of a range expansion with those of conspecific hermaphrodites occupying the core of the species' range, or between the native and exotic ranges of invasive species.

\subsection{Evaluation of statistics for inbreed- ing and population differentiation in the context of sex-allocation evolu- tion}

Our study has also considered how the evolutionary stable sex allocation of a hermaphroditic metapopulation relates to measures of inbreeding and population differentiation. The rationale for these considerations is twofold. First, the metapopulation phenomena of both subdivision of the population into small demes (which in itself causes inbreeding relative to the metapopulation as a whole) and the turnover of populations (which causes enhanced inbreeding as an outcome of local population bottlenecks and the resulting strong within-deme co-ancestry) are well known to affect both genetic measures of differentiation and inbreeding such as $F_{S T}[31,45,47,50]$ and, as explored here, patterns of sex allocation. And second, sex-ratio theory forges a direct link between inbreeding and the evolutionarily stable sex allocation $[3,5,17]$. In this section, we first draw attention to the contrast between $F_{S T}$ and $F_{I S}$ as predictors of hermaphroditic sex allocation, and then compare $F_{S T}$ with other measures that have been proposed to characterise population differentiation.

Our simulations highlight that the sex allocation of a hermaphroditic metapopulation is predicted much better by $F_{S T}$ than by $F_{I S}$, and that the latter is relatively insensitive to population turnover. Previous theoretical work and empirical observation to date have clearly established the dependence of the ESS sex allocation on within-population inbreeding [3, 5, $17]$, which can be measured by $F_{I S}$. Indeed, the reduced allocation to male function in partially or wholly self-fertilizing species, which have high $F_{I S}$, is well understood as the result of the local mate competition caused by selfing. Hermaphroditic plants with a colonizing habit, and thus subject to metapopulation dynamics, are often self-fertilizing and show allocation patterns consistent with female bias, particularly low pollen-ovule ratios [27]. Although we expect selection under self-fertilization to favour female biases allocation, our simulations should caution us away from invoking within-population selfing as the sole basis of selection for such bias, because a history of population turnover may also have contributed to it. Indeed, the extent of this enhancement is predicted by the additional inbreeding due to population subdivision and the bottlenecks of colonisation, as measured by $F_{S T}$. Note that in species that self-fertilize only or mainly during the process of colonisation but that outcross 
bioRxiv preprint doi: https://doi.org/10.1101/2020.05.08.080929; this version posted May $9,2020$. The copyright holder for this preprint (which was not certified by peer review) is the author/funder, who has granted bioRxiv a license to display the preprint in perpetuity. It is made available under aCC-BY-NC-ND 4.0 International license.

Sex allocation, inbreeding, and measures of population differentiation in hermaphroditic metapopulations

once mates become available with population growth (as assumed in most of our simulations), $F_{I S}$ will be low, reflecting the local outcrossing rate, yet selection at the metapopulation level will favour female-biased sex allocation all the same. In such cases, the ESS sex allocation is predicted by $F_{S T}$ on its own, and biases can more confidently be attributed to demographic processes. We suggest, therefore, that the association between sex allocation and population subdivision and turnover revealed by our simulations would best be empirically evaluated by comparing allocation to male and female functions between regions of the geographic range of an outcrossing species (low $F_{I S}$ ) that differ in their regional value of $F_{S T}$.

Our study has also highlighted important differences in how sex allocation relates to measures of population differentiation other than $F_{S T}$. It is clear from our results that this relationship is substantially tighter for $F_{S T}$ than for $G_{S T}$, its derivatives, and especially Jost's $D$. Two points are worth discussing. First, we found that elevated $F_{S T}$ provides a reasonable prediction for female-biased sex allocation irrespective of the underlying demographic causes, i.e., irrespective of whether $F_{S T}$ is elevated because of high population turnover, or low among-deme migration, or small numbers of colonists, or because colonists come from one rather than from many demes (colonisation follows a propagule-pool rather than a migrant-pool model). This is a useful result: whereas inferring the demographic processes underway in a metapopulation with any precision will typically be difficult or impossible, estimating $F_{S T}$ on the basis of appropriate genetic data is relatively easy.

Second, our results emphasise the clear superiority of $F_{S T}$ over the other measures assessed for relating sex allocation to population structure, especially Jost's $D$. This finding provides a graphic illustration of the intimate conceptual connection of $F_{S T}$ to evolutionary theory in general and to inbreeding in particular [38]. There has been substantial discussion in the literature over the relative virtues of different measures of population differentiation. Statistics such as the normalised versions of $G_{S T}$ and Jost's $D$ have been proposed as solutions, for example, to the sensitivity of $F_{S T}$ to the mutation rate when it is of the order of or greater than the migration rate (reviewed in [38] and [75]), these other measures will tend to be poor replacements for $F_{S T}$ when the aim is to connect to evolutionary theory, in which its incorporation has a long history. As Whitlock [38] has pointed out, $F_{S T}$ may be sensitive to all evolutionary forces, including drift, migration and selection. Moreover, $F_{S T}$ was originally developed as a measure of inbreeding, so its close association with the EES sex allocation in our simulations, driven by local mate competition through inbreeding, should not be surprising [15]. In contrast, whereas $F_{S T}$ measures deviations from random mating due to population structure, Jost's $D$, which measures deviations from total genetic differentiation, is not connected in any formal way to a population's history of inbreeding and is even rather insensitive to some processes that affect differentiation itself, such as genetic drift [38]. It is also slower to reach equilibrium than is $F_{S T}$ [76], a fact likely to render it less useful for characterising populations subject demographic fluctuations in a metapopulation. Our simulations reveal that to the extent that $D$ is sensitive to, say, the migration rate, this sensitivity interacts in a complex way with the population turnover rate, as do (though apparently less severely) the normalised measures of $G_{S T}$, whereas the dependence of $F_{S T}$ on the migration rate is monotonically negative, irrespective of the extinction rate (compare Figure 3A with Figures 3E, F and G). This complex dependence of $D$ on the interaction between migration and extinction has not, to our knowledge, been noted previously, but it exemplifies the inadequacy of $D$ as an index that might offer insights in evolutionary or demographic processes.

\section{Authors' contributions}

JRP conceived the study. CR wrote the simulation program and performed the simulations. SN and CM contributed to the implementation of the simulation program. JRP and CR wrote the ms.

\section{Competing interests}

The authors declare no conflict of interest.

\section{Acknowledgements}

CR was funded by grants awarded to JRP by the grant Swiss National Science Foundation (31003A_163384) and by the University of Lausanne. $\mathrm{CM}$ was supported by Swiss National Science Foundation grant PCEFP3181243. SN was supported by Swiss National Science Foundation grant 31003A_138180. We are grateful to Jérôme Goudet for helpful discussions. The simulations were performed on the Core Cluster of the Institut Français de Bioinformatique (IFB) (ANR-11INBS-0013).

\section{References}

1. Düsing, K. Die regulierung des geschlechtsverhältnisses bei der vermehrung der menschen, tiere und pflanzen (Fischer, 1884).

2. Fisher, R. A. The genetical theory of natural selection (Oxford University Press, 1958).

3. Hamilton, W. D. Extraordinary sex ratios. Science 156, 477-488 (1967). 
bioRxiv preprint doi: https://doi.org/10.1101/2020.05.08.080929; this version posted May $9,2020$. The copyright holder for this preprint (which was not certified by peer review) is the author/funder, who has granted bioRxiv a license to display the preprint in perpetuity. It is made available under aCC-BY-NC-ND 4.0 International license.

Sex allocation, inbreeding, and measures of population differentiation in hermaphroditic metapopulations

4. Taylor, P. \& Bulmer, M. Local mate competition and the sex ratio. J. Theor. Biol. 86, 409-419 (1980).

5. West, S. Sex allocation (Princeton University Press, 2009).

6. Read, A. F., Narara, A., Nee, S., Keymer, A. \& Day, K. Gametocyte sex ratios as indirect measures of outcrossing rates in malaria. Parasitology 104, 387-395 (1992).

7. Molbo, D. \& Parker, E. Mating structure and sex ratio variation in a natural population of Nasonia vitripennis. Proc. R. Soc. Lond. B Biol. Sci. 263, 1703-1709 (1996).

8. West, S. A., Shuker, D. M. \& Sheldon, B. C. Sexratio adjustment when relatives interact: a test of constraints on adaptation. Evolution 59, 12111228 (2005).

9. Shuker, D. M., Pen, I., Duncan, A. B., Reece, S. E. $\&$ West, S. A. Sex ratios under asymmetrical local mate competition: theory and a test with parasitoid wasps. Am. Nat. 166, 301-316 (2005).

10. Grillenberger, B. et al. Genetic structure of natural Nasonia vitripennis populations: validating assumptions of sex-ratio theory. Mol. Ecol. 17, 2854-2864 (2008).

11. Molbo, D., Machado, C. A., Sevenster, J. G., Keller, L. \& Herre, E. A. Cryptic species of fig-pollinating wasps: implications for the evolution of the figwasp mutualism, sex allocation, and precision of adaptation. Proc. Natl. Acad. Sci. U.S.A. 100, 5867-5872 (2003).

12. Fellowes, M. D., Compton, S. G. \& Cook, J. M. Sex allocation and local mate competition in Old World non-pollinating fig wasps. Behav. Ecol. Sociobiol. 46, 95-102 (1999).

13. Song, Z. et al. Local resource competition affects sex allocation in a bird: experimental evidence. Anim. Behav. 121, 157-162 (2016).

14. Reece, S. E., Drew, D. R. \& Gardner, A. Sex ratio adjustment and kin discrimination in malaria parasites. Nature 453, 609-614 (2008).

15. Taylor, P. D. An inclusive fitness model for dispersal of offspring. J. Theor. Biol. 130, 363-378 (1988).

16. Aviles, L., Mc Cormack, J., Cutter, A. \& Bukowski, T. Precise, highly female-biased sex ratios in a social spider. Proc. R. Soc. Lond. B Biol. Sci. 267, 1445-1449 (2000).

17. Charnov, E. L. The theory of sex allocation (Princeton University Press, 1982).

18. Brunet, J. Sex allocation in hermaphroditic plants. Trends Ecol. Evol. 7, 79-84 (1992).
19. Charlesworth, D. \& Charlesworth, B. Allocation of resources to male and female functions in hermaphrodites. Biol. J. Linn. Soc. 15, 57-74 (1981).

20. Schärer, L. Tests of sex allocation theory in simultaneously hermaphroditic animals. Evolution 63, 1377-1405 (2009).

21. Lloyd, D. G. Selection of combined versus separate sexes in seed plants. Am. Nat. 120, 571-585 (1982).

22. Clark, A. B. Sex ratio and local resource competition in a prosimian primate. Science $\mathbf{2 0 1}, 163-$ 165 (1978).

23. Bulmer, M. G. \& Taylor, P. D. Dispersal and the sex ratio. Nature 284, 448-449 (1980).

24. Frank, S. A. Hierarchical selection theory and sex ratios I. General solutions for structured populations (1986).

25. Harris, M. S. \& Pannell, J. R. Roots, shoots and reproduction: sexual dimorphism in size and costs of reproductive allocation in an annual herb. Proc. R. Soc. Lond. B Biol. Sci. 275, 2595-2602 (2008).

26. Cutter, A. D. Reproductive transitions in plants and animals: selfing syndrome, sexual selection and speciation. New Phytol. 224, 1080-1094 (2019).

27. Sicard, A. \& Lenhard, M. The selfing syndrome: a model for studying the genetic and evolutionary basis of morphological adaptation in plants. Ann. Bot. 107, 1433-1443 (2011).

28. Lemen, C. Allocation of reproductive effort to the male and female strategies in wind-pollinated plants. Oecologia 45, 156-159 (1980).

29. Schärer, L. \& Pen, I. Sex allocation and investment into pre-and post-copulatory traits in simultaneous hermaphrodites: the role of polyandry and local sperm competition. Philos. Trans. R. Soc. BBiol. Sci. 368, 20120052 (2013).

30. Vekemans, X. \& Hardy, O. J. New insights from fine-scale spatial genetic structure analyses in plant populations. Mol. Ecol. 13, 921-935 (2004).

31. Whitlock, M. C. \& McCauley, D. E. Some population genetic consequences of colony formation and extinction: genetic correlations within founding groups. Evolution 44, 1717-1724 (1990).

32. Ives, A. R. \& Whitlock, M. C. Inbreeding and metapopulations. Science 295, 454-455 (2002).

33. Haag, C. R., Hotinger, J. W., Riex, M. \& Ebert, D. Strong inbreeding depression in a Daphnia metapopulation. Evolution 56, 518-526 (2002). 
bioRxiv preprint doi: https://doi.org/10.1101/2020.05.08.080929; this version posted May $9,2020$. The copyright holder for this preprint (which was not certified by peer review) is the author/funder, who has granted bioRxiv a license to display the preprint in perpetuity. It is made available under aCC-BY-NC-ND 4.0 International license.

Sex allocation, inbreeding, and measures of population differentiation in hermaphroditic metapopulations

34. Haag, C. R., Riek, M., Hottinger, J. W., Pajunen, V. I. \& Ebert, D. Genetic diversity and genetic differentiation in Daphnia metapopulations with subpopulations of known age. Genetics 170, 1809-1820 (2005).

35. Pannell, J. \& Obbard, D. Probing the primacy of the patch: what makes a metapopulation? J. Ecol. 91, 485-488 (2003).

36. Aviles, L. Interdemic selection and the sex ratio: a social spider perspective. Am. Nat. 142, 320-345 (1993).

37. Jost, L. GST and its relatives do not measure differentiation. Mol. Ecol. 17, 4015-4026 (2008).

38. Whitlock, M. C. G'(ST) and D do not replace FST. Mol. Ecol. 20, 1083-1091 (2011).

39. Leng, L. \& Zhang, D.-X. Measuring population differentiation using GST or D? A simulation study with microsatellite DNA markers under a finite island model and nonequilibrium conditions. Mol. Ecol. 20, 2494-2509 (2011).

40. Pannell, J. R. \& Fields, P. D. Evolution in subdivided plant populations: concepts, recent advances and future directions. New Phytol. 201, 417-432 (2014).

41. Alcala, N., Goudet, J. \& Vuilleumier, S. On the transition of genetic differentiation from isolation to panmixia: what we can learn from GST and D. Theor. Popul. Biol. 93, 75-84 (2014).

42. Verity, R. \& Nichols, R. A. What is genetic differentiation, and how should we measure it-GST, D, neither or both? Mol. Ecol. 23, 4216-4225 (2014).

43. Jost, L. et al. Differentiation measures for conservation genetics. Evol. Appl. 11, 1139-1148 (2018).

44. Wang, J. On the measurements of genetic differentiation among populations. Genetics Research 94, 275-289 (2012).

45. Wade, M. J. \& McCauley, D. E. Extinction and recolonization: their effects on the genetic differentiation of local populations. Evolution 42, 9951005 (1988).

46. Slatkin, M. Gene flow and genetic drift in a species subject to frequent local extinctions. Theor. Popul. Biol. 12, 253-262 (1977).

47. Pannell, J. R. \& Charlesworth, B. Neutral genetic diversity in a metapopulation with recurrent local extinction and recolonization. Evolution 53, 664676 (1999).

48. Keenan, K., McGinnity, P., Cross, T. F., Crozier, W. W. \& Prodöhl, P. A. diveRsity: An R package for the estimation and exploration of population genetics parameters and their associated errors. Methods Ecol. Evol. 4, 782-788 (2013).
49. Rousset, F. Effective size in simple metapopulation models. Heredity 91, 107-111 (2003).

50. Pannell, J. R. \& Charlesworth, B. Effects of metapopulation processes on measures of genetic diversity. Philos. Trans. R. Soc. B-Biol. Sci. 355, 1851-1864 (2000).

51. Werren, J. Sex ratio adaptations to local mate competi-tion in a parasitic wasp. Science 208, 1157-1159 (1980).

52. Frank, S. A. Hierarchical selection theory and sex ratios. II. On applying the theory, and a test with fig wasps. Evolution 39, 949-964 (1985).

53. Herre, E. A. Sex ratio adjustment in fig wasps. Science 228, 896-898 (1985).

54. Herre, E. A. Optimality, plasticity and selective regime in fig wasp sex ratios. Nature 329, 627629 (1987).

55. Cruden, R. W. Pollen-ovule ratios: a conservative indicator of breeding systems in flowering plants. Evolution 31, 32-46 (1977).

56. Lloyd, D. G. Self-and cross-fertilization in plants. II. The selection of self-fertilization. Int. J. Plant Sci. 153, 370-380 (1992).

57. Charlesworth, D. \& Charlesworth, B. The effect of investment in attractive structures on allocation to male and female functions in plants. Evolution 41, 948-968 (1987).

58. Bell, G. On the function of flowers. Proc. R. Soc. Lond. B Biol. Sci. 224, 223-265 (1985).

59. Stanton, M. L., Snow, A. A. \& Handel, S. N. Floral evolution: attractiveness to pollinators increases male fitness. Science 232, 1625-1627 (1986).

60. Barrett, S. C. H., Harder, L. D. \& Worley, A. C. The comparative biology of pollination and mating in flowering plants. Philos. Trans. R. Soc. London, Ser. B 351, 1271-1280 (1996).

61. Hardy, I. C. in Concepts and research methods (Cambridge University Press UK, 2002).

62. Smith, J. M. Group selection and kin selection. Nature 201, 1145-1147 (1964).

63. Bulmer, M. G. \& Taylor, P. D. Dispersal and the sex ratio. Nature 284, 448-449 (1980).

64. Moody-Weis, J., Antonovics, J., Alexander, H. M. \& Pilson, D. Predicting local colonization and extinction dynamics from coarser-scale surveys. Ecography 31, 61-72 (2008).

65. Giles, B. E. \& Goudet, J. Genetic differentiation in Silene dioica metapopulations: estimation of spatiotemporal effects in a successional plant species. Am. Nat. 149, 507-526 (1997).

66. Dorken, M. E., Freckleton, R. P. \& Pannell, J. R. Small-scale and regional spatial dynamics of an annual plant with contrasting sexual systems. $J$. Ecol. 105, 1044-1057 (2017). 
67. Eppley, S. M. \& Pannell, J. R. Sexual systems and Supplementary material measures of occupancy and abundance in an annual plant: testing the metapopulation model. Am. Nat. 169, 20-28 (2007).

68. Obbard, D. J., Harris, S. A. \& Pannell, J. R. Sexual systems and population genetic structure in an annual plant: testing the metapopulation model. Am. Nat. 167, 354-366 (2006).

69. Pannell, J., Eppley, S., Dorken, M. \& Berjano, R. Regional variation in sex ratios and sex allocation in androdioecious Mercurialis annua. J. Evol. Biol. 27, 1467-1477 (2014).

70. Pannell, J. Widespread functional androdioecy in Mercurialis annua L.(Euphorbiaceae). Biol. $J$. Linn. Soc. 61, 95-116 (1997).

71. Pannell, J. Variation in sex ratios and sex allocation in androdioecious Mercurialis annua. J. Ecol., 57-69 (1997).

72. Dorken, M. E. \& Pannell, J. R. Density-dependent regulation of the sex ratio in an annual plant. $A m$. Nat. 171, 824-830 (2008).

73. Korbecka, G., Hamilton, A. \& Pannell, J. Mixed mating in polyploid androdioecious populations of Mercurialis annua estimated using multilocus genotypes in progeny arrays. Ann. Bot. 107, 1057-1061 (2011).

74. Russell, J. \& Pannell, J. Sex determination in dioecious Mercurialis annua and its close diploid and polyploid relatives. Heredity 114, 262-271 (2015).

75. Meirmans, P. G. \& Hedrick, P. W. Assessing population structure: FST and related measures. Mol. Ecol. Resour. 11, 5-18 (2011).

76. Ryman, N. \& Leimar, O. Effect of mutation on genetic differentiation among nonequilibrium populations. Evolution 62, 2250-2259 (2008).

77. Weir, B. S. \& Cockerham, C. C. Estimating Fstatistics for the analysis of population structure. Evolution 38, 1358-1370 (1984).

78. Nei, M. \& Chesser, R. K. Estimation of fixation indices and gene diversities. Ann. Hum. Genet. 47, 253-259 (1983).

79. Hedrick, P. W. A standardized genetic differentiation measure. Evolution 59, 1633-1638 (2005). 
bioRxiv preprint doi: https://doi.org/10.1101/2020.05.08.080929; this version posted May 9, 2020. The copyright holder for this preprint (which was not certified by peer review) is the author/funder, who has granted bioRxiv a license to display the preprint in perpetuity. It is

Sex allocation, inbreeding, and measures of population differentiation in hermaphroditic metapopulations

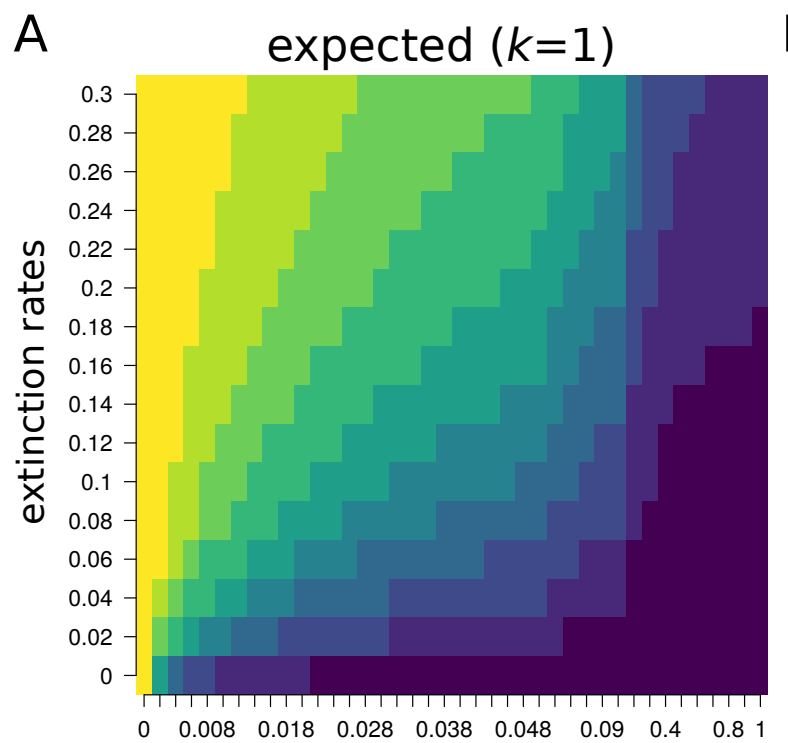

B simulated $(k=1)$

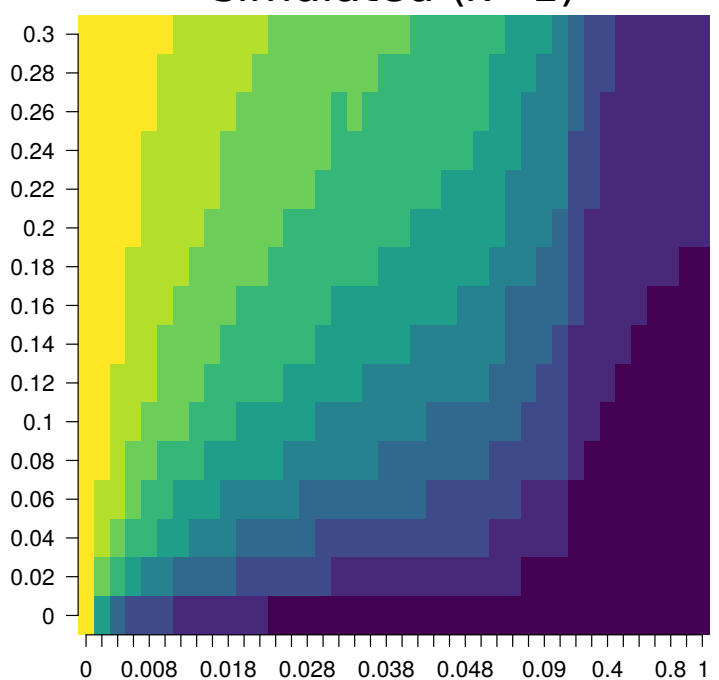

\section{D simulated $(k=2)$}

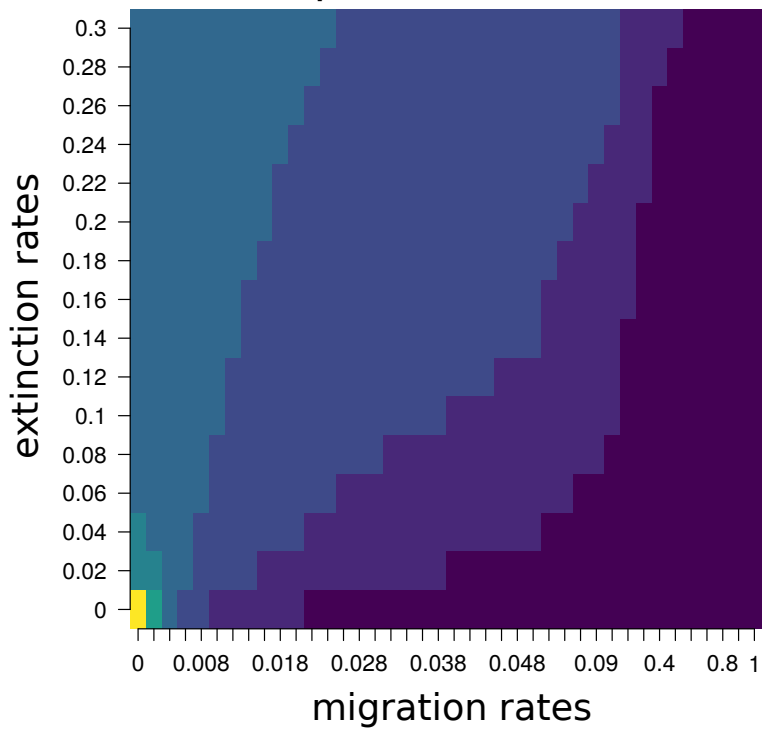

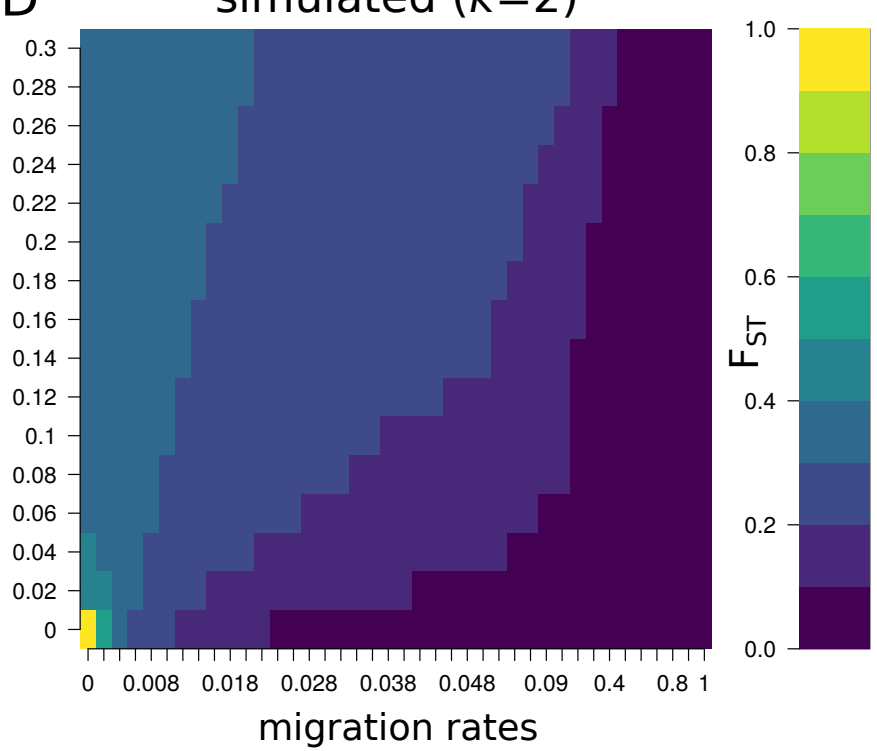

Figure S1. Joint effects of migration and extinction on expected and simulated $F_{S T}$. Each bin reports the median $F_{S T}$ value over 20 simulations of 20 unlinked neutral markers. The metapopulation was composed of 1,000 demes with a maximum of 100 diploid individuals per deme. The neutral mutation rate was 0.00001 per generation, and the selfing rate was set to zero. The expected $F_{S T}$ is equal to :

$F_{S T}=\left(q r-\frac{1}{2 \cdot N_{e}}\right) * \frac{2 . N_{e}}{2 \cdot N_{e}-1}$, where

$q r=\frac{\frac{1}{2 \cdot N_{e}}+\frac{e}{2 . k}-\frac{e}{4 . k \cdot N_{e}}}{1-\left(1-\frac{1}{2 \cdot N_{e}}\right) *\left[(1-m)^{2} *(1-e)+e *\left(1-\frac{1}{2 \cdot k}\right) * \frac{1}{(2 . k-1)}\right]}$,

$N_{e}$ is the carrying capacity of each deme expressed in the number of diploid individuals, $k$ the number of diploid individuals recolonizing an empty deme, and $m$ is the migration rate expressed in proportion of the population composed by immigrants each generation. 
bioRxiv preprint doi: https://doi.org/10.1101/2020.05.08.080929; this version posted May 9, 2020. The copyright holder for this preprint (which was not certified by peer review) is the author/funder, who has granted bioRxiv a license to display the preprint in perpetuity. It is made available under aCC-BY-NC-ND 4.0 International license.
Sex allocation, inbreeding, and measures of population differentiation in hermaphroditic metapopulations

number of colonizers $-1=2=10$
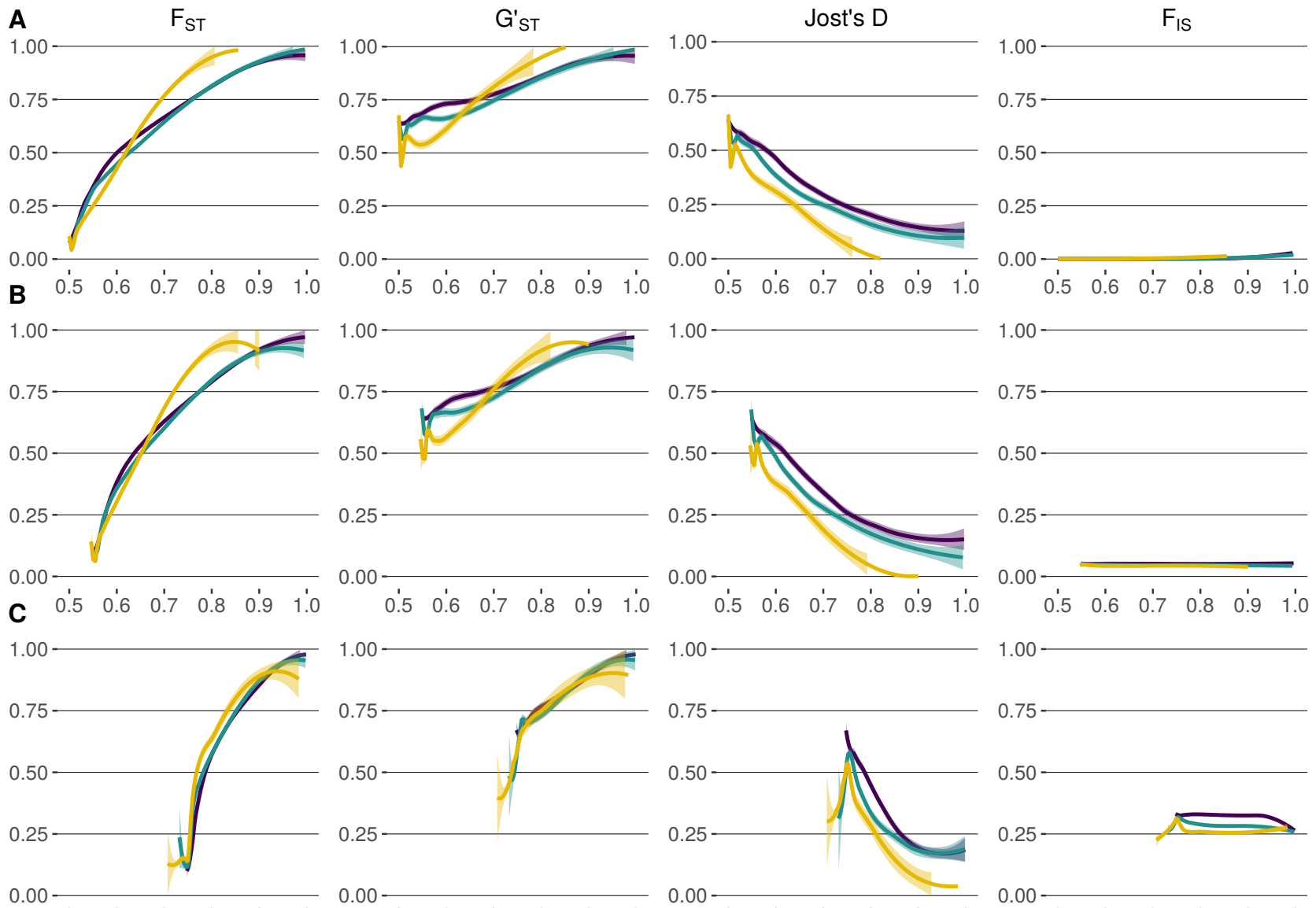

$1.00-$
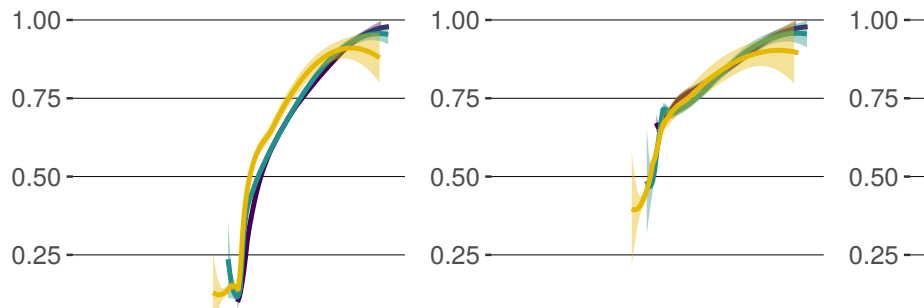

0.75

$0.00-$

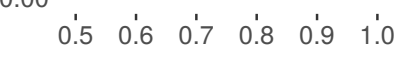

0.00
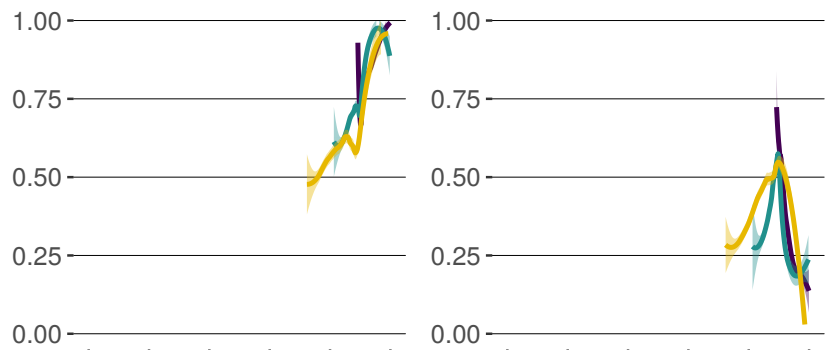

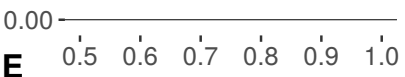

$0.00-$

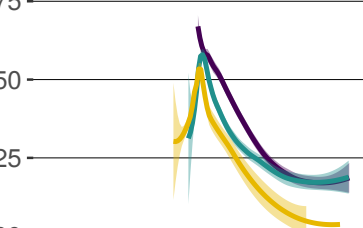

$0.50-$

$0.25-$
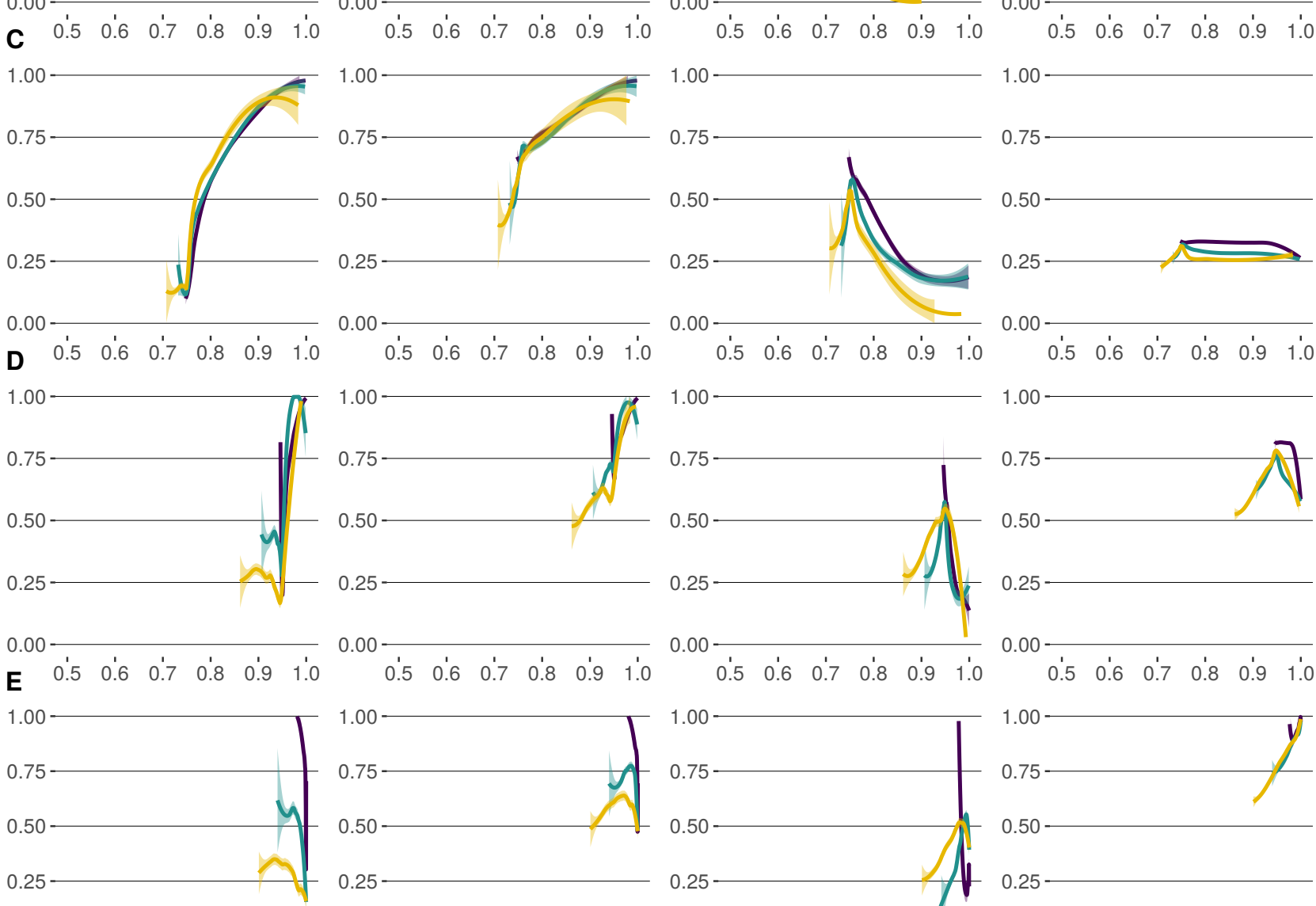

$0.50-$

$0.25-$

$0.5 \quad 0.6 \quad 0.7 \quad 0.8 \quad 0.9 \quad 1.0$

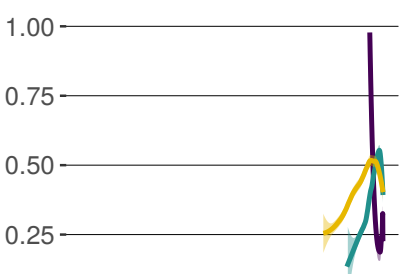

$0.00-$

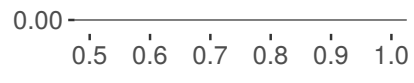

female allocation

$\begin{array}{llllll}0.00 & 0.6 & 0.7 & 0.8 & 0.9 & 1.0\end{array}$

female allocation

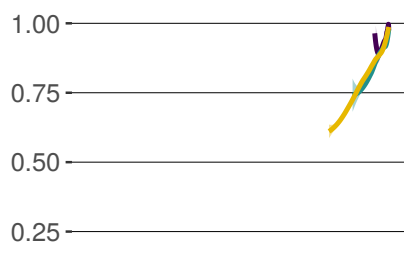

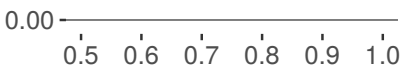
female allocation

Figure S2. Relationship between female allocation and patterns of genetic diversity and differentiation. Five self-fertilisation rates were explored and shown on each row: (A) $s=0$; (B) $s=0.1$; (C) $s=0.5$; (D) $s=0.9$ and (E) $s=1$. 
bioRxiv preprint doi: https//doi.org/10.1101/2020.05.08 .080929 : this version posted May 9 2020. The copyright holder for this preprint (which was not certified by peer review) is the author/funder, who has granted bioRxiv a license to display the preprint in perpetuity. It is Sex allocation, inbreeding, and measures of population differentiation in hermaphroditic metapopulations

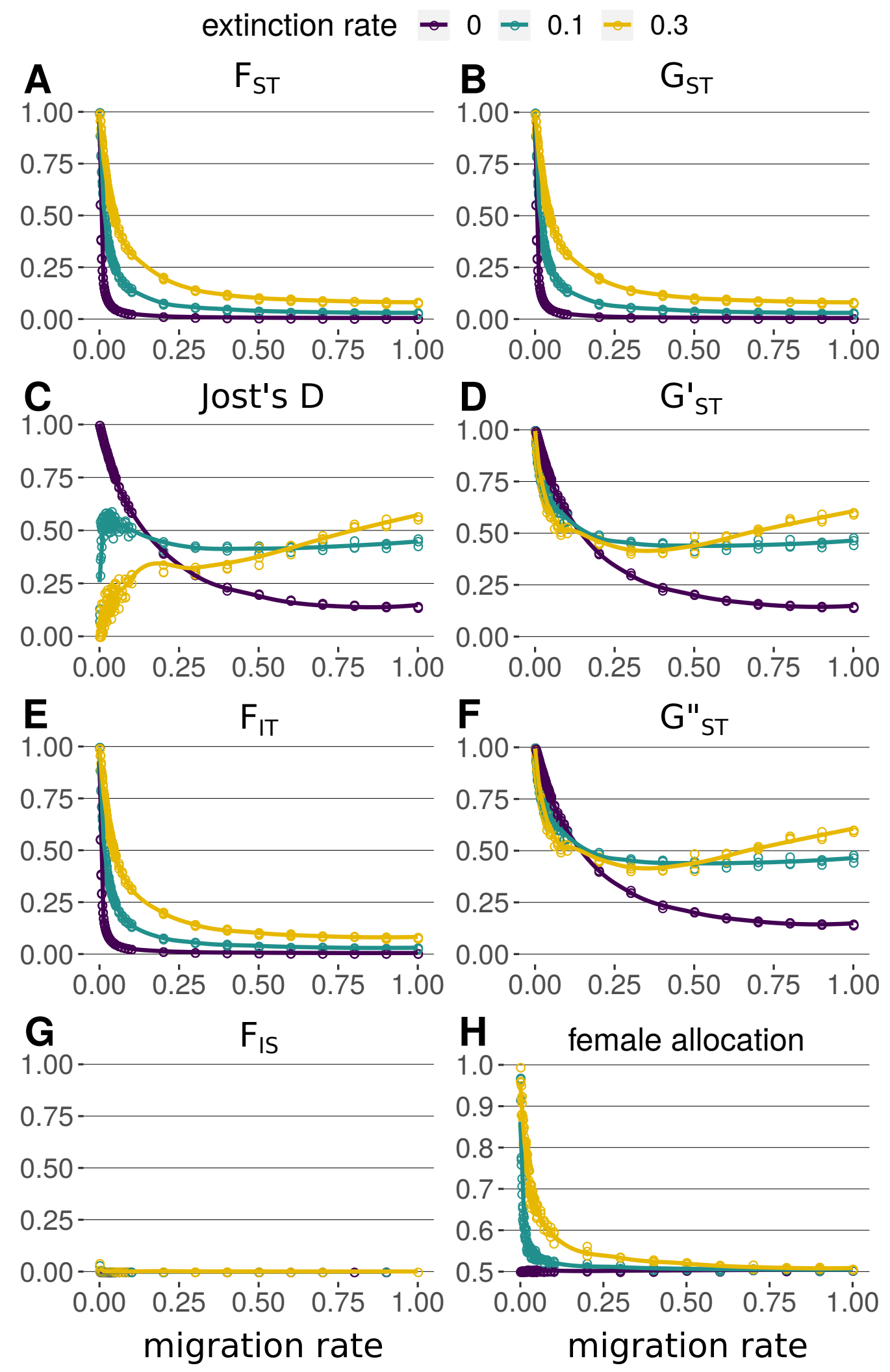

Figure S3. Effects of migration and extinction on various genetic and phenotypic variables for $k=2$ colonizers. The lines indicate different extinction rates explored: $e=0$ (violet), $e=0.1$ (blue) and $e=0.3$ (yellow). 
bioRxiv preprint doi: https:/doi.org/10.1101/2020 05.08.080929; this version posted May 9,2020 . The copyright holder for this preprint (which was not certified by peer review) is the author/funder, who has granted bioRxiv a license to display the preprint in perpetuity. It is

Sex allocation, inbreeding, and measures of population differentiation in hermaphroditic metapopulations

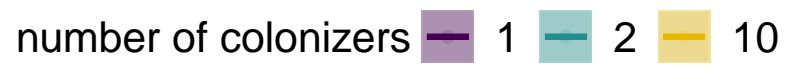

A propagule pool model
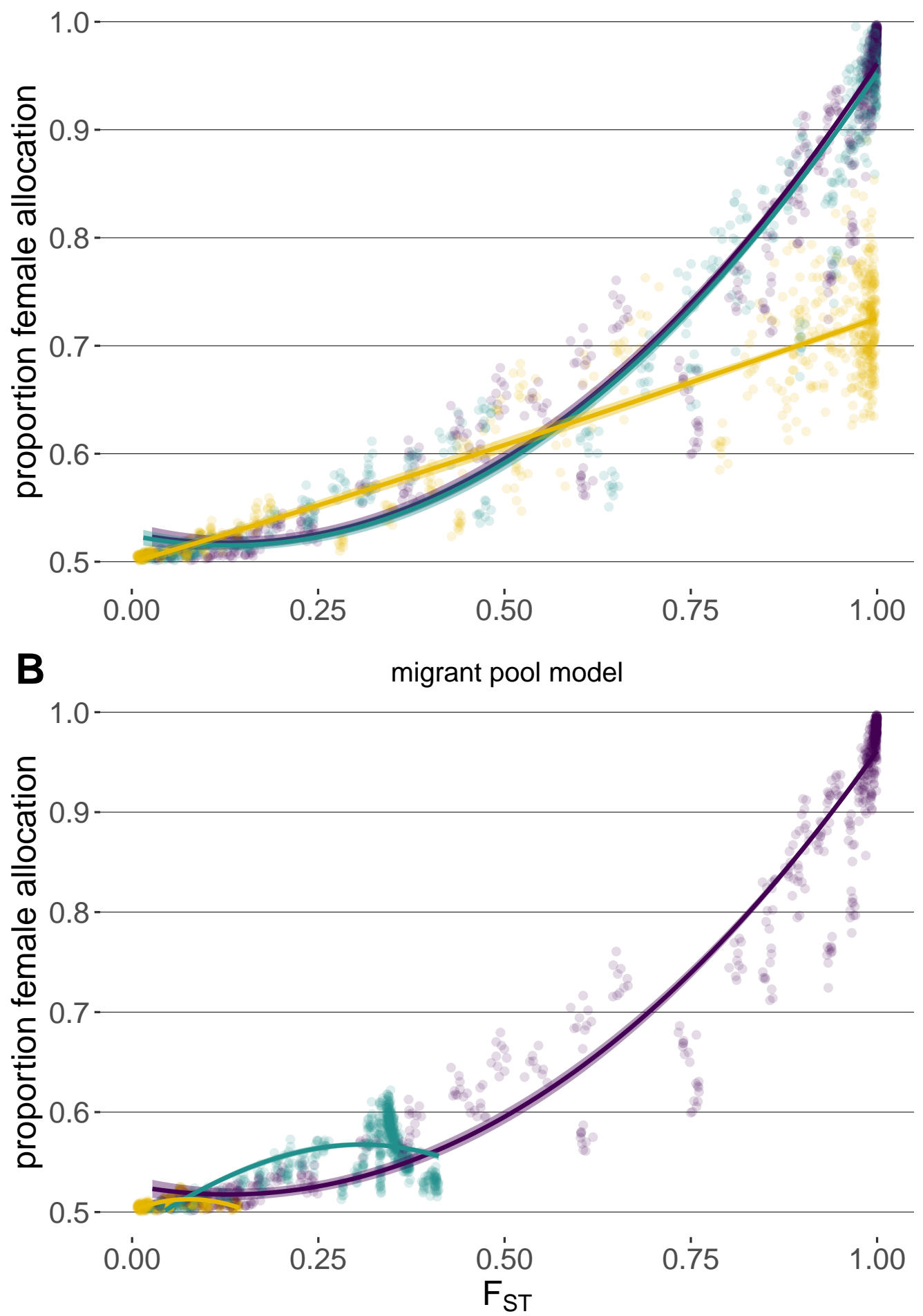

Figure S4. Relationship between genetic differentiation measured in terms of $F_{S T}$ and female allocation for two recolonization models. 
bioRxiv preprint doi: https://doi.org/10.1101/2020.05.08.080929; this version posted May 9, 2020. The copyright holder for this preprint (which was not certified by peer review) is the author/funder, who has granted bioRxiv a license to display the preprint in perpetuity. It is Sex allocation, inbreeding, and measures of population differentiation in hermaphroditic metapopulations

Table S1. Statistics measured during simulations

\begin{tabular}{ccc}
\hline Statistic & Symbol & Reference \\
\hline Inbreeding coefficient & $F_{I S}$ & {$[77]$} \\
Individual inbreeding coefficient relative to the total population & $F_{I T}$ & {$[77]$} \\
Population differentiation & $F_{S T}$ & {$[77]$} \\
Population differentiation & $G_{S T}$ & {$[78]$} \\
Standardized $G_{S T}$ & $G_{S T}^{\prime}$ & {$[79]$} \\
Standardized $G_{S T}$ & $G_{S T}^{\prime \prime}$ & {$[75]$} \\
Population differentiation & $D_{j o s t}$ & {$[37]$} \\
Expected $F_{S T}$ value based on extinction rate, & $\exp F_{S T}$ & {$[49]$} \\
migration rate, and local population carrying capacity & $N_{\text {tot }}$ & - \\
\hline Total number of individuals present in the whole metapopulation & &
\end{tabular}


bioRxiv preprint doi: https://doi.org/10.1101/2020.05.08.080929; this version posted May 9, 2020. The copyright holder for this preprint (which was not certified by peer review) is the author/funder, who has granted bioRxiv a license to display the preprint in perpetuity. It is Sex allocation, inbreeding, and measures of population differentiation in hermaphroditic metapopulations 